\title{
Os caminhos que levaram à criação do Portal de Tecnologia Assistiva do Curso de Terapia Ocupacional da UFRJ ${ }^{1}$
}

\author{
Miryam Bonadiu Pelosi ${ }^{a}$, Vera Lúcia Vieira de Souza, \\ Rodrigo Cintra Vasquez Dias ${ }^{c}$, Lindinete Telles Menezes ${ }^{d}$, Lila Mara Oliveira ${ }^{d}$ \\ aTerapeuta ocupacional, Doutora em Educação, Universidade do Estado do Rio de Janeiro - UERJ, \\ Professora Adjunta da Universidade Federal do Rio de Janeiro - UFRJ, Rio de Janeiro, RJ, Brasil \\ ${ }^{\text {b}}$ Terapeuta ocupacional, Doutoranda em Educação, Universidade do Estado do Rio de Janeiro - UERJ, \\ Professora Assistente da Universidade Federal do Rio de Janeiro - UFRJ, Rio de Janeiro, RJ, Brasil \\ 'Engenheiro elétrico, Mestrando pela Universidade Estadual de Campinas - UNICAMP, Campinas, SP, Brasil \\ dProfessoras da Sala de Recursos Multifuncionais, Secretaria Municipal de Educação - SME, \\ Rio de Janeiro, RJ, Brasil
}

\begin{abstract}
Resumo: O Portal de Tecnologia Assistiva nasceu do projeto Formação de Professores das Salas Multifuncionais para o Desenvolvimento da Comunicação Alternativa com Alunos com Necessidades Educacionais Especiais e tem o objetivo de democratizar as informações na área de tecnologia assistiva. O estudo do qual ele foi o principal produto objetivou planejar, implementar e avaliar os efeitos de uma formação destinada aos professores das Salas de Recursos Multifuncionais no município do Rio de Janeiro. Para tanto, foi pesquisado o perfil dos professores, dos alunos acompanhados por eles e da forma de funcionamento dessas salas. Participaram do estudo, cuja metodologia foi a pesquisa-ação, 19 professores. Os instrumentos para coleta de dados compreenderam questionários, cadernos de campo e a análise do material de Comunicação Alternativa, atividades pedagógicas adaptadas, histórias e jogos desenvolvidos no curso. As estratégias de formação foram adequadas à demanda do grupo e a metodologia foi extremamente favorável, pois permitiu que o grupo tivesse uma participação ativa durante todo o processo de formação. O compartilhamento do material na internet foi precursor da ideia de construção do Portal de Tecnologia Assistiva e a participação dos professores com suas considerações foram fundamentais para o desenvolvimento do sítio eletrônico.
\end{abstract}

Palavras-chave: Tecnologia Assistiva, Educação Especial, Terapia Ocupacional, Auxiliares de Comunicação para Pessoas com Deficiência.

\section{The paths that led to the creation of the Assistive Technology Portal of the UFRJ Occupational Therapy Course}

\begin{abstract}
The Assistive Technology Portal originated from a project called "Multifunction Room Teachers' Qualification for Alternative Communication Development of Students with Special Educational Needs" with the purpose to democratize information in the Assistive Technology area. This Portal was the main product of this study, whose objective was to plan, implement, and assess the effects of a qualification designed to teachers of Multifunctional Resource Rooms in Rio de Janeiro. To this end, we researched the profiles of teachers and students, as well as the operation of these rooms. Nineteen teachers participated in this study, which used the action survey methodology. Data collection tools comprised questionnaires, field textbooks and Alternative Communication material analysis, adapted pedagogical activities, and stories and games developed in the course.
\end{abstract}

Autor para correspondência: Miryam Bonadiu Pelosi, Universidade Federal do Rio de Janeiro, Av. dos Flamboyants, 1250, bloco 1, ap. 505, Barra da Tijuca, CEP 22776-070, Rio de Janeiro, RJ, Brasil, e-mail: miryam.pelosi@gmail.com

Recebido em 31/8/2011; Revisão em 16/4/2012; Aceito em 19/5/2012. 
The qualification strategies have been customized to the group's demands, and the methodology adopted was extremely favorable because it enabled the group to have an active participation throughout the qualification process. Sharing material on the internet originated the idea of developing the Assistive Technology Portal, and the participation of teachers with their views was essential for the development of the website.

Keywords: Assistive Technology, Special Education, Occupational Therapy, Communication Aids for the Disabled.

\section{Introdução}

A Política Nacional de Educação Especial na Perspectiva da Educaçáo Inclusiva atual garante o acesso à escolarização no ensino regular aos alunos com necessidades educacionais especiais e o Atendimento Educacional Especializado complementar. Esse atendimento deve ser organizado em Salas de Recursos Multifuncionais (SRM), disponibilizando recursos pedagógicos e de acessibilidade que eliminem as barreiras para a aprendizagem (BRASIL, 2008).

As atividades desenvolvidas no atendimento educacional especializado não têm a função de substituir a escolarização, mas, sim, complementar e/ou suplementar a formação dos alunos, objetivando a autonomia e a independência na escola e fora dela (BRASIL, 2007).

Essas salas são equipadas com vários recursos de tecnologia assistiva, como computadores com softwares para o desenvolvimento da comunicação alternativa, mouse adaptado, acionadores, reglete, sorobá, lupas, entre outros. As salas de recursos multifuncionais receberam os programas Boardmaker e Speaking Dynamically Pro.

O Boardmaker é um programa de computador que contém um banco de dados gráfico, com mais de 4.500 símbolos de comunicação pictórica - PCS em português do Brasil. Os símbolos de comunicação pictórica formam um sistema de comunicação pictográfica, criado no início dos anos 1980 pela fonoaudióloga americana Roxanna Mayer Johnson e compóem atualmente o conjunto de símbolos mais difundido em todo o mundo. As características incluem: desenhos simples e claros, de fácil reconhecimento; símbolos adequados para usuários de qualquer idade e que estão divididos em seis categorias de palavras: social, pessoas, verbos, descritivo, substantivos e miscelânea.

Já o software Speaking Dynamically Pro - SDP transforma o computador em um eficaz recurso de educação e de comunicação alternativa. É um programa que trabalha integrado ao Boardmaker, permitindo criar inúmeras atividades interativas educacionais e de comunicação, com acessibilidade total. O acesso ao SDP pode ser feito com o auxílio do mouse, teclado ou por meio de acionadores externos, utilizando-se os sistemas de varredura. As atividades desenvolvidas com esse programa funcionam de maneira dinâmica, pois o software possibilita a criação de pranchas de comunicação interligadas com funçôes programáveis em suas células. Possui mais de 100 funções programáveis, que permitem escrever e editar textos na área de mensagem, abrir programas, exibir flmes e reproduzir arquivos de som

Para auxiliar o aluno com necessidades especiais, o professor precisa escolher, introduzir, treinar e orientar recursos que favoreçam a comunicação, o aprendizado e a realização das tarefas. Além disso, o recurso deve permitir a participação em brincadeiras na sala e no recreio, a conversa na hora do lanche e a inclusão em atividades complementares da escola, como a aula de Educaçáo Física ou a aula de Música e, para isso, precisa conhecer a área da tecnologia assistiva.

A tecnologia assistiva é uma área abrangente, que envolve conhecimentos sobre mobilidade alternativa, adequação da posiçáo sentada, adaptaçóes de acesso ao computador, transporte adaptado, acessibilidade de ambientes, e a Comunicação Alternativa e Ampliada (CAA).

A CAA, área de conhecimento de base para esse estudo, compreende a utilização de recursos alternativos para complementar ou substituir a fala ou a escrita de pessoas com dificuldades comunicativas. Essas dificuldades podem ser transitórias ou permanentes, advindas de deficiências, incapacidades ou relacionadas ao processo de envelhecimento.

Para favorecer a comunicação podem ser usados gestos, sinais da Língua Brasileira de Sinais, expressóes faciais, pranchas com o alfabeto, fotografias ou símbolos pictográficos, comunicadores ou até mesmo sistemas mais sofisticados como tablets e computadores com softwares especiais.

A comunicação é considerada alternativa quando o indivíduo não apresenta outra forma de comunicação e considerada ampliada quando o indivíduo possui 
alguma comunicação, mas essa não é suficiente para suas trocas sociais.

O recurso de CAA mais utilizado nas escolas é a prancha de comunicação (PELOSI, 2008). A confecçấo desse recurso requer conhecimentos sobre as diferentes formas de simbolizar um conceito, dados sobre seleção de vocabulário e sua organização, e o aprofundamento em diferentes programas de computador que facilitam a construção do recurso. Além desse saber, o profissional responsável pelo desenvolvimento da CAA precisa de tempo disponível para confeccionar os recursos que possam atender às necessidades comunicativas da criança em diferentes contextos.

Os estudos têm mostrado que, mesmo nas formações em serviço na área de CAA no Brasil em que a avaliação do curso é considerada satisfatória, a confecção de novos recursos de comunicação alternativa é raramente realizada após o término deles (PELOSI, 2000, 2008).

Muitas empresas desenvolvedoras de softwares para comunicação alternativa no exterior têm procurado criar espaços de compartilhamento de pranchas de comunicação e atividades desenvolvidas com símbolos em seus websites ${ }^{2}$. São exemplos dessa prática o BoardmakerShare ${ }^{3}$, da empresa Mayer Jonhson, desenvolvedora de programas utilizados no Brasil, como o Boardmaker e o Speaking Dynamically Pro, por serem programas cujos símbolos estão traduzidos para o português e por possuírem sintetizador de voz também em português.

Outros exemplos são o site da empresa portuguesa Imagina, que desenvolveu os aplicativos Escrita com Símbolos, Invento e Aventuras, todos em português, e que também possui um espaço de compartilhamento de atividades ${ }^{4}$, o site Classroom Suite Activity Exchange ${ }^{5}$, da empresa Intellitools, que possui programas como o Classroom Suite e Overlaymaker, ou, ainda, o site da empresa Sensory Software International, que desenvolveu o software The Grid2 e que também possui um compartilhamento de atividade on-line ${ }^{6}$.

Todas essas iniciativas auxiliam os profissionais que trabalham na área de tecnologia assistiva a criar recursos personalizados a partir de ideias ou atividades desenvolvidas por outros profissionais, mas trazem questôes para os brasileiros, como a dificuldade com a língua inglesa em que estão construídos, além da necessidade de ter instalados os diferentes programas para que o download seja executado e o aplicativo possa ser utilizado.

Fica claro, então, que uma área de conhecimento tão extensa como a tecnologia assistiva necessita de uma ação interdisciplinar. Profissionais como terapeutas ocupacionais, fonoaudiólogos, fisioterapeutas, professores, psicólogos, assistentes sociais, oftalmologistas, especialistas em audição, protéticos e engenheiros somam seus conhecimentos nessa área.

$\mathrm{O}$ aumento na complexidade e na quantidade de equipamentos de tecnologia assistiva vêm criando a necessidade de ampliação das formaçóes em serviço, além da inclusão do assunto nos cursos de graduação nas mais diferentes áreas.

Para esclarecer a parceria estabelecida entre a Terapia Ocupacional e a educação no município do Rio de Janeiro desde 1992 com os primeiros cursos de formação da área de comunicação alternativa, é importante compreender o trabalho do terapeuta ocupacional e sua relação com a área da tecnologia assistiva.

A Terapia Ocupacional é uma profissão da área de Saúde que trabalha com atividades humanas, planejando, organizando e reabilitando as açôes cotidianas das pessoas, e possibilitando que elas exerçam os papéis que necessitam ou desejam (LAW, 2005). Seu campo de ação é a preservação da saúde e a participação na vida por meio do envolvimento na ocupação, e o seu foco de intervenção é a disfunção ocupacional (AMERICAN..., 2002).

A dificuldade de comunicação oral ou escrita ou a ausência de comunicação provocam uma disfunção ocupacional, que é traduzida no cotidiano da pessoa como uma dificuldade de participaçáo em atividades sociais, laborais ou de educação.

A Terapia Ocupacional, por intermédio da avaliação do perfil ocupacional da pessoa e da análise do seu desempenho ocupacional com a identificaçâo de suas habilidades, limitaçóes e necessidades, indica o recurso de tecnologia assistiva, realiza as modificaçóes necessárias e orienta as pessoas envolvidas no uso dessa tecnologia (CANADIAN..., 2003).

O curso de Terapia Ocupacional da Universidade Federal do Rio de Janeiro, sensível à necessidade de ampliação do conhecimento nessa área, vem pesquisando e realizando ações de extensão nas diferentes áreas da tecnologia assistiva.

O projeto de pesquisa Formação de Professores das Salas de Recursos Multifuncionais para o Desenvolvimento da Comunicaçáo Alternativa com os Alunos com Necessidades Educacionais Especiais foi uma dessas iniciativas e objetivou planejar, implementar e avaliar os efeitos de uma formação destinada aos professores das salas de recursos multifuncionais que trabalhavam no município do 
Rio de Janeiro. Para tanto, pesquisou o perfil dos professores e dos alunos acompanhados por eles e a forma de funcionamento dessas salas.

Como principal produto, foi criado o Portal de Tecnologia Assistiva do Curso de Terapia Ocupacional da UFRJ, espaço de compartilhamento de pranchas de comunicação e atividades com símbolos na língua portuguesa.

\section{Metodologia}

O modelo utilizado foi a pesquisa-ação e o projeto foi desenvolvido em quatro etapas: submissão à comissão de ética; contato inicial com os professores já designados para as Salas Multifuncionais e pré-teste; organização e implementação do curso de formação; e acompanhamento dos trabalhos desenvolvidos nas Salas Multifuncionais, através da supervisão de casos.

Participaram do estudo 19 professores das Salas de Recursos Multifuncionais, e os instrumentos para coleta de dados compreenderam questionários, cadernos de campo e a análise do material de comunicação alternativa, as atividades pedagógicas adaptadas, as histórias e os jogos desenvolvidos no curso.

Em todos os instrumentos foram realizadas análises quantitativas das questôes fechadas e análise de conteúdo das questôes descritivas. A técnica utilizada foi a análise categorial, que funciona por operaçôes de desmembramento do texto em categorias, segundo reagrupamentos analógicos (BARDIN, 2009).

Os dados coletados nas perguntas fechadas do estudo foram organizados em banco de dados, usando-se os softwares Microsoft Office Access e Excel. O primeiro, auxiliando a organização dos dados em categorias, para facilitar a análise, e o segundo auxiliando a quantificaçáo dos resultados.

A equipe que trabalhou no projeto foi composta pela coordenadora e uma professora auxiliar de pesquisa, duas bolsistas Faperj de Iniciação Científica, duas bolsistas Pibex da UFRJ e duas bolsistas de Treinamento e Capacitação Técnica da Faperj que eram professoras das Salas de Recursos Multifuncionais da SME/RJ.

O trabalho foi desenvolvido no laboratório de informática de uma escola municipal no centro da cidade do Rio de Janeiro.

Os trabalhos produzidos pelos professores foram compartilhados no Dropbox ${ }^{7}$ e, posteriormente, em um portal ${ }^{8}$.

\section{Resultados}

A formação teve a duração total de 80 horas, divididas em 23 encontros de $3 \mathrm{~h} 30$ cada, que ocorreram semanalmente, de abril a novembro de 2010.

As estratégias de organização das aulas e a escolha dos temas levaram em conta as necessidades e os interesses dos profissionais, consideraram os materiais que estavam disponíveis nas SRM e objetivaram a formação de profissionais para o desenvolvimento da comunicação alternativa.

A Terapia Ocupacional contribuiu com a análise situacional e a fragmentação do conhecimento em pequenas tarefas, a aproximação do conteúdo das situaçóes reais do dia a dia do professor e o conhecimento da comunicação alternativa e dos alunos com necessidades educacionais especiais.

Serão apresentados os dados obtidos a partir da análise do questionário Avaliação do Curso e do Professor, que expressam a opinião de 17 dos 19 professores das Salas de Recursos Multifuncionais, os quais responderam ao instrumento, e o resultado da produção dos professores ao longo da formação.

$\mathrm{Na}$ opinião dos professores, as pesquisadoras foram assíduas (17), demonstraram domínio do assunto (17), revelaram clareza e objetividade na exposição (16), organizaram adequadamente o curso (16), estimularam a discussão em aula e a participação dos alunos (17) e houve um bom relacionamento entre os professores e os alunos (17).

Quanto ao curso, os objetivos iniciais foram alcançados para a maior parte do grupo (13), e na opinião de quatro dos participantes houve mais pontos positivos do que negativos. O conteúdo mostrou-se adequado a sua prática para 15 dos participantes e, para a maioria, as atividades práticas foram úteis para auxiliar o trabalho de comunicação alternativa na escola (13). O ritmo do curso foi plenamente satisfatório para 12 dos participantes e com mais pontos positivos do que negativos para cinco dos professores. Todo o grupo considerou que o curso correspondeu aos seus interesses e aspiraçóes.

Nas perguntas abertas, os professores destacaram a dinâmica (12) e o conhecimento dos professores (6), os materiais e as práticas com estudo de casos (17).

Os aspectos negativos destacados por 12 dos respondentes foram: excesso de informaçôes (4), excesso de atividades (2), pouco tempo de aula (2), falta de ênfase em vídeos (3), não ter aulas de manhã (2) e outros temas que foram sinalizados apenas por 
um participante como longas discussóes de casos ou grupo pequeno de participantes.

A produção dos professores ao longo da formação revelou que foram desenvolvidas 51 pranchas de comunicação; 41 atividades pedagógicas adaptadas; e 15 atividades relacionadas a atividades de lazer, como histórias e jogos. O total da produção compreendeu 354 pranchas de trabalho, que compuseram as diferentes atividades.

A participação dos professores variou de 1 a 54 pranchas confeccionadas, sendo 134 pranchas estáticas para serem impressas e 220 pranchas dinâmicas para serem usadas no computador.

As atividades foram desenvolvidas com os softwares Boardmaker e Speaking Dynamically.

Os professores produziram vários recursos com o software Boardmaker, que incluíram: fichas com símbolos, fotografias, letras, sílabas, palavras e números; pranchas de comunicação; atividades pedagógicas adaptadas; e jogos infantis adaptados. Atividades de alfabetizaçáo, de comunicação e provas adaptadas foram desenvolvidas utilizando o software Speaking Dynamically. Esse programa possibilita a construção de pranchas dinâmicas para uso no próprio computador.

Além desses programas específicos, utilizou-se o software PowerPoint ${ }^{9}$ para a elaboração de histórias e atividades de leitura e interpretação de textos. Toda a produçáo dos professores foi impressa, plastificada e organizada com a ajuda das quatro bolsistas do curso de Terapia Ocupacional.

Cada professor recebeu sua produção impressa em cores e teve a oportunidade de plastificar o material com o auxílio de uma plastificadora que ficou à disposiçáa dos professores no decorrer do curso. As atividades desenvolvidas no computador, com o auxílio dos softwares PowerPoint e Speaking Dynamically, foram revisadas pela pesquisadora e discutidas com os participantes nos encontros de formação.

No decorrer do curso, as produçóes dos professores ficaram disponíveis para todo o grupo, de maneira compartilhada, no site Dropbox. Os professores foram convidados a acessar as atividades e, com o programa instalado nos seus computadores, puderam acompanhar em tempo real as modificações e inclusões que eram feitas no banco de dados. Todo o material foi organizado como arquivo $\mathrm{BDR}^{10}$, para ser acessado e modificado por qualquer usuário dos programas de comunicação alternativa. As informaçóes foram salvas, também, em formato $\mathrm{PDF}^{11}$, para que pudessem ser acessadas por qualquer pessoa que tivesse interesse na comunicação alternativa, mesmo que náo tivesse os programas Boardmaker e o Speaking Dynamically.

As atividades foram organizadas por categorias, a saber: atividades de ciências, matemática, português, pré-escolares, atividades pedagógicas, pranchas de comunicação, jogos adaptados, histórias e símbolos soltos. As pranchas de comunicação apresentaram temas como: atividades escolares, rotina, calendário, histórias, animais, receita, alimentação, frutas, brinquedos e brincadeiras, passeios, coisas que o usuário gosta de fazer, vestuário, coisas que o usuário quer fazer, família e sentimentos.

Os jogos reuniram atividades conhecidas das crianças e outras que foram criadas pelos professores. Atividades como batalha naval, senha de animais e cores, bingo dos sentidos, jogo das sílabas, jogo das cores, leitura e interpretação de histórias, cara a cara, jogo de adivinhação do tipo Quem sou eu também fizeram parte do acervo.

Foram também desenvolvidas pranchas eletrônicas para serem utilizadas no computador e acessadas com o mouse ou acionador externo ligado ao mouse adaptado $^{12}$.

O compartilhamento do material na internet foi precursor da ideia de construçáo de um portal para socialização dos trabalhos, o qual se tornou o principal produto dessa pesquisa.

Os professores participaram das discussóes da criação do portal e fizeram consideraçôes baseados nas suas experiências de uso do arquivo compartilhado no Dropbox.

Os problemas elencados pelos professores na utilização do Dropbox estavam relacionados ao fato de náo haver a possibilidade de utilização de mecanismos de busca. Os pontos levantados pelos professores foram: dificuldade em localizar um determinado trabalho por nome, autor ou data, impossibilidade de localizar trabalhos recentes, buscar trabalhos por palavras-chave e identificar os diferentes aplicativos que possuíam atividades de um mesmo tema.

O Portal de Tecnologia Assistiva do Curso de Terapia Ocupacional da UFRJ foi concebido como um depositório de recursos que teve como ponto de partida a produção dos professores do curso de formação.

O desenvolvimento do portal considerou a simplicidade de acesso para o profissional da área, a possibilidade de visualização dos recursos distribuídos antes de ser executado o download, as diferentes estratégias de busca (categoria, tipo de software, nome da prancha, data da atividade, autor, número 
de acessos e palavras-chave) e a democratização das informaçôes, pois o portal hospeda atividades desenvolvidas com diferentes aplicativos, incluindo aplicativos gratuitos ou desenvolvidos com softwares amplamente acessíveis, como o Microsoft Word e o Microsoft PowerPoint.

A Figura 1 mostra a página inicial do portal com seus mecanismos de busca: caixa de texto, Recursos distribuídos e Busca avançada.
A Figura 2 mostra com mais detalhes o mecanismo de Busca avançada, a Figura 3, o resultado dessa busca por categorias e por atividades, na Figura 4.

Todas as atividades possuem uma cópia em PDF que pode ser baixada e impressa. Além disso, houve a preocupação de que o portal náo precisasse de manutenção especializada depois de finalizado seu desenvolvimento e design, de forma que seu conteúdo pudesse ser "alimentado" sem a necessidade de um programador.

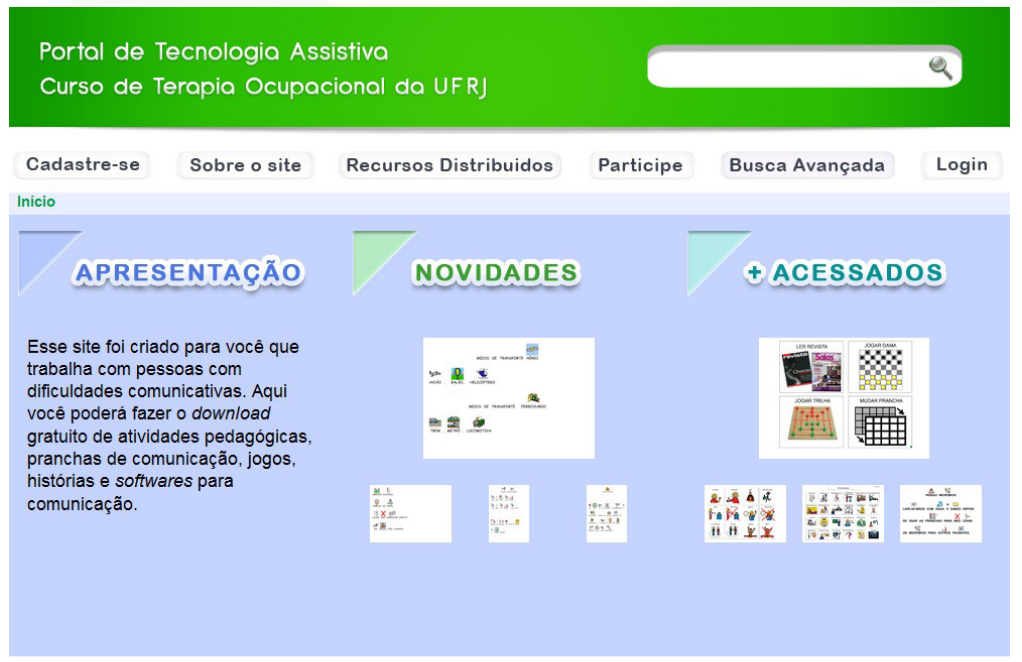

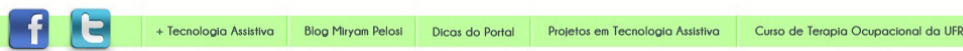

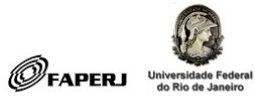

Figura 1. Página inicial do Portal de Tecnologia Assistiva do Curso de Terapia Ocupacional da UFRJ.

Portal de Tecnologia Assistiva

Curso de Terapia Ocupacional da UFRJ

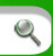

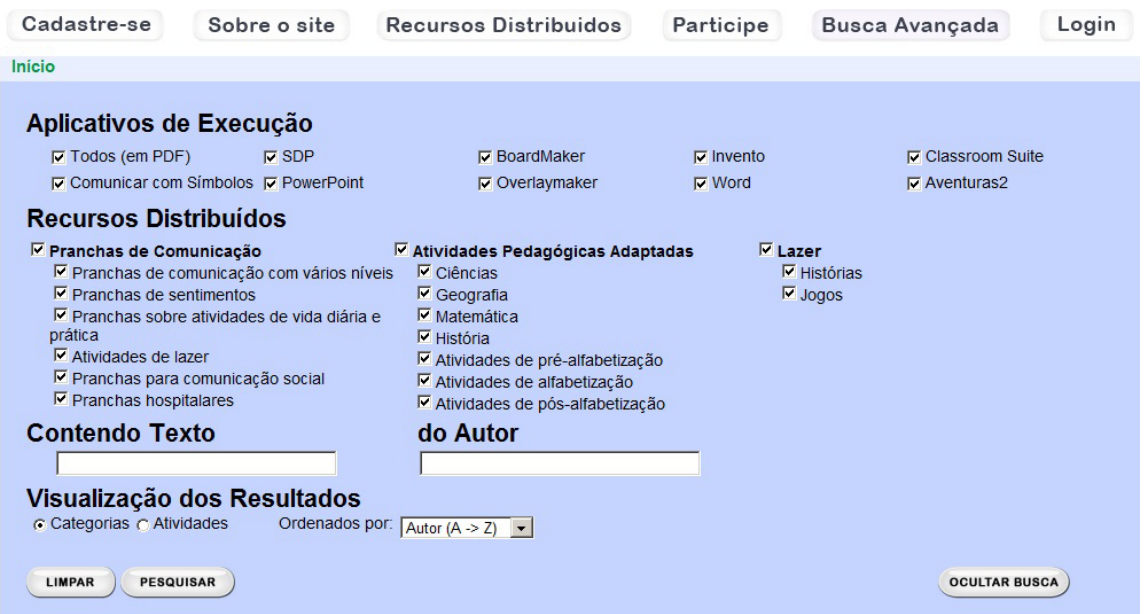

Figura 2. Detalhes do mecanismo de busca do Portal de Tecnologia Assistiva. 
O portal está estruturado para fazer o upload de qualquer atividade. As atividades poderão ser inseridas por profissionais que trabalham na área de tecnologia assistiva, estudantes, familiares e usuários de comunicação alternativa que queiram compartilhar suas ideias com seus pares. Quando o material é inserido, ele permanece invisível até que uma das pessoas responsáveis pelo portal analise a atividade, sua descrição e categorias e autorize a disponibilização para a comunidade, como mostra a Figura 5.

\section{Pranchas de comunicação com vários níveis (16) \\ Conjunto de pranchas interligadas que têm 0 objetivo de favorecer a comunicação de maneira abrangente. \\ Pranchas para comunicação social (189) \\ Pranchas que auxiliam a interação social de usuários com dificuldades comunicativas.}

\section{Atividades de pós- alfabetização (36)}

Atividades desenvolvidas para usuários que já estão alfabetizados.

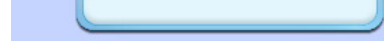

\section{Pranchas de sentimentos (46)}

Pranchas que auxiliam o usuário a expressar seus sentimentos.

\section{Pranchas hospitalares (132)}

\section{Pranchas desenvolvidas para favorecer a comunicação de usuários hospitalizados com} dificuldades comunicativas.

\section{Histórias (86)}

Histórias infantis adaptadas ou histórias criadas para ensinar conceitos. Ótimo recurso para treinar o uso de acionador.

\section{Pranchas sobre atividades de vida diária e prática (191) \\ Pranchas sobre temas como: alimentação, higiene, cuidados com a casa e animais, compras, escola e trabalho.}

\section{Atividades de pré- alfabetização (66)}

Atividades desenvolvidas para mação com 0 processo de alfabetização.

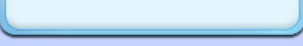

\section{Jogos (47)}

Memória, dominó, baralhos, batalha naval, cara a cara, entre outros, adaptados com símbolos.

\section{Atividades de lazer (190)}

Pranchas relacionadas a atividades de lazer como passeios, viagens, hobbies, etc.

Figura 3. Resultado da busca apresentado por categorias.

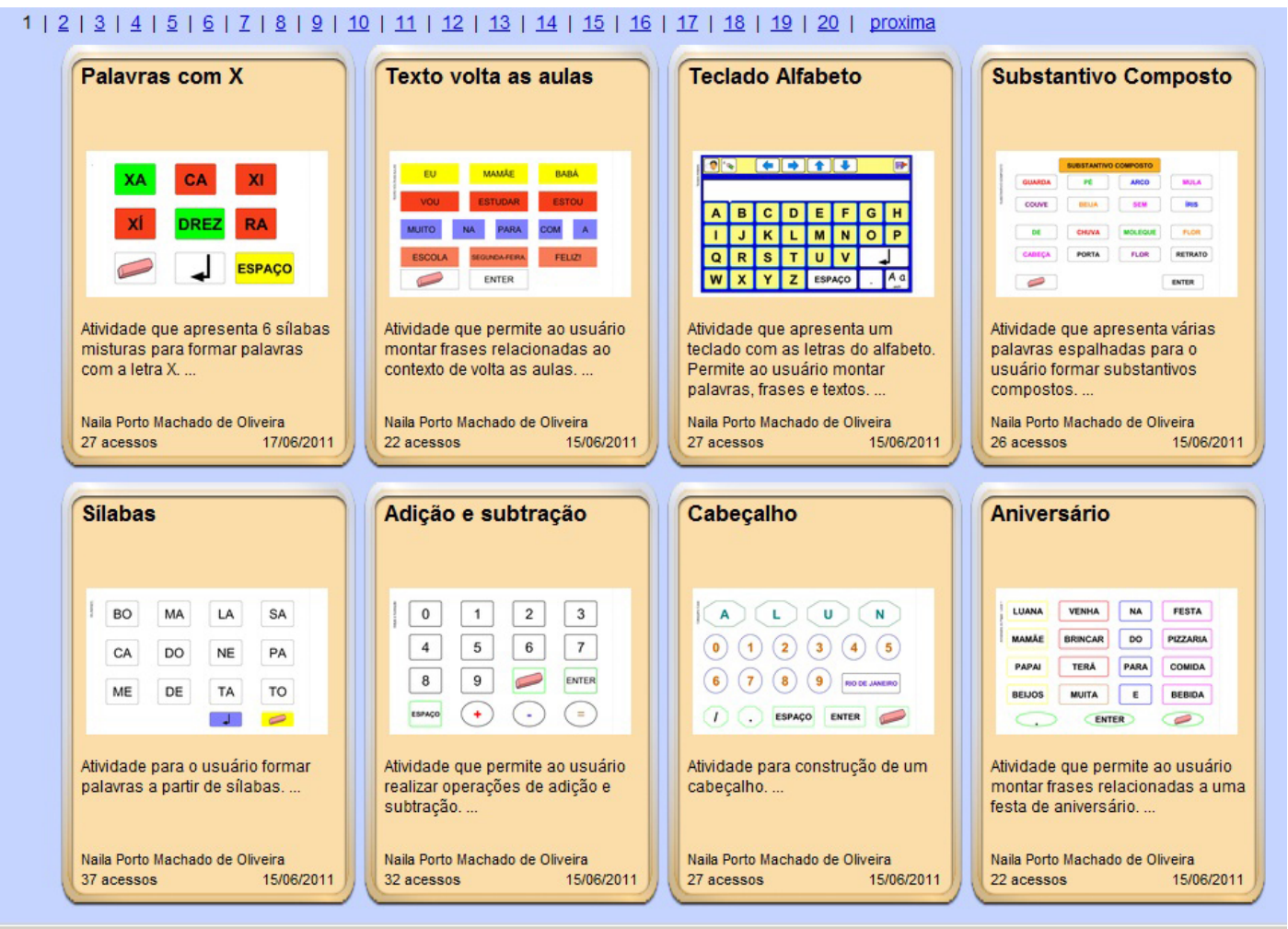

Figura 4. Resultado da busca apresentado por atividades. 


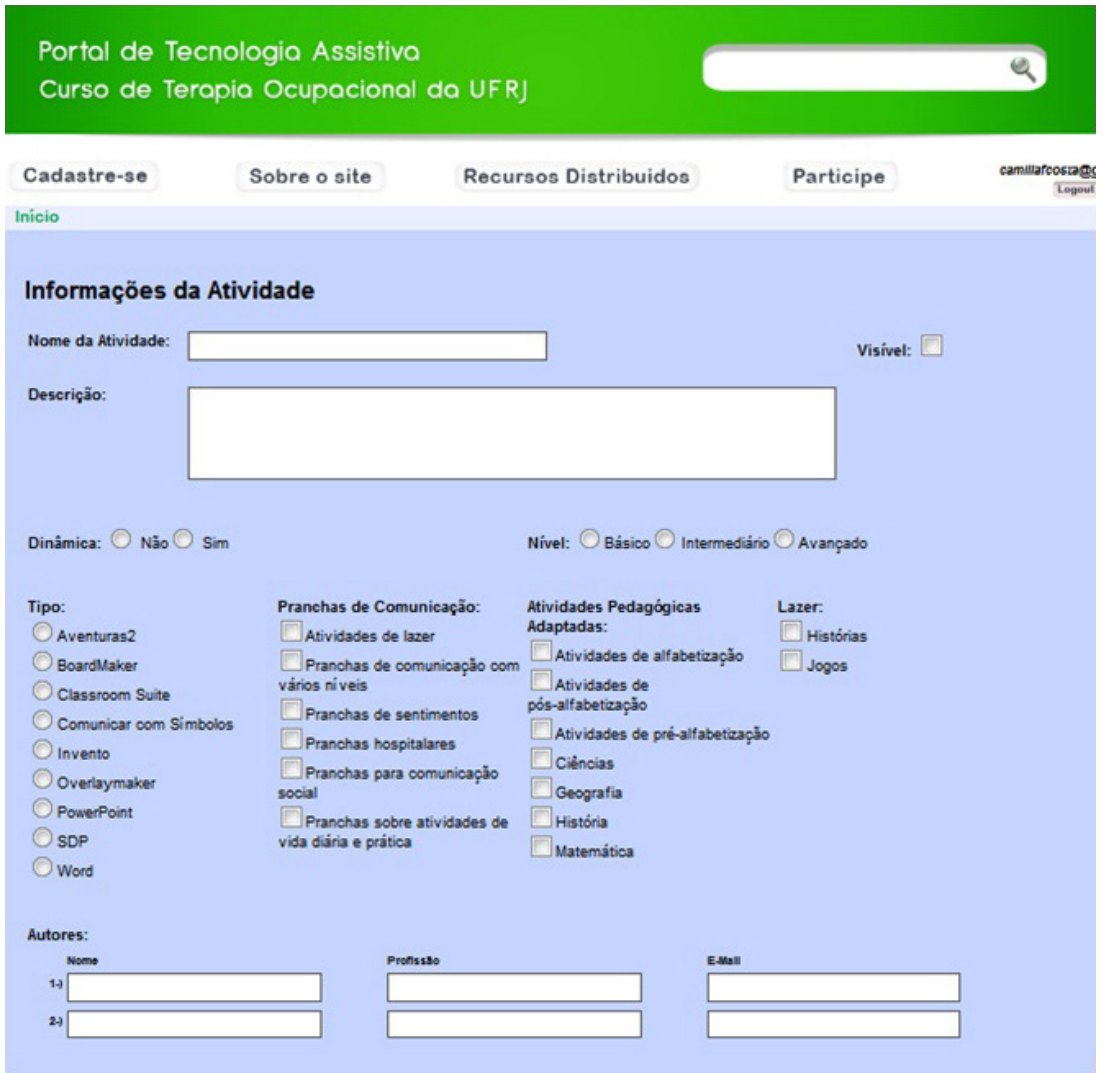

Figura 5. Página para o upload de atividades.

\section{Discussão}

A formação favoreceu o aprendizado dos professores na área de comunicação alternativa e possibilitou a produçáo de muitos recursos que foram utilizados com seus alunos nas salas de recursos. A estratégia de discussão de casos de alunos da escola, com vídeos, foi apontada como essencial no processo de formação.

A fundamentação teórica e a organização do curso basearam-se no conhecimento dos professores, seus interesses e disponibilidade.

A partilha das atividades desenvolvidas pelos professores, por meio de uma pasta compartilhada no site Dropbox, foi estimulante, assim como a correção dos trabalhos e a oportunidade de imprimir e plastificar o material produzido. Uma professora declarou:

Estava em casa no domingo e o meu computador começou a mostrar que meus colegas estavam trabalhando, tive que fazer uma prancha também.

As estratégias de formação foram adequadas à demanda do grupo. A metodologia da pesquisa-ação foi extremamente favorável, pois permitiu que o grupo tivesse uma participação ativa durante todo o processo de formação.

Depois da introdução da plastificadora nos encontros de formação, os professores fizeram fila para utilizar o recurso e as produçôes aumentaram muito.

A produtividade foi o principal termômetro do envolvimento do grupo com o processo. É claro que a produçáo estava relacionada a uma série de aspectos individuais como: maior familiaridade com o computador; disponibilidade do uso do software nas Salas de Recursos; e alunos com necessidade imediata de atividades de comunicação alternativa. A produção variou de 1 a 54 pranchas confeccionadas e aqueles que tiveram mais dificuldade de produção utilizaram os materiais confeccionados pelos colegas. Muitos aproveitaram os debates da formação para repensar a organização e a funcionalidade de seus materiais já construídos e os trouxeram para apresentar ao grupo.

O compartilhamento do material na internet foi precursor da ideia de construção do Portal de Tecnologia Assistiva e a participação dos professores, com suas consideraçóes, foi fundamental para o desenvolvimento do site. A forma como foi concebido permitiu que ele se tornasse um grande acervo 
on-line com vida própria, mas com mecanismos que garantem a qualidade de seus aplicativos.

\section{Considerações finais}

O papel da universidade não se restringe à pesquisa. Suas açóes em extensão possibilitam que o conhecimento desenvolvido dentro dos seus muros seja utilizado diretamente pela população.

O Grupo de Pesquisa em Tecnologia Assistiva do Curso de Terapia Ocupacional da UFRJ, sensibilizado com essa necessidade, coordenou a pesquisa de formação, colheu dados sobre o funcionamento das salas, dos alunos e dos professores, que foram fundamentais para a organização da formação que atendeu as necessidades e os anseios do grupo.

Como produto desse trabalho, construiu um portal que favorecerá a formação de novos professores e profissionais da Saúde e a socialização das informaçôes na área de tecnologia assistiva.

\section{Referências}

AMERICAN OCCUPATIONAL THERAPY ASSOCIATION - AOTA. Occupational Therapy Pratice Framework: domain and process. American Journal of Occupational Therapy, New York, v. 56, n. 6, p. 609-633, 2002. http://dx.doi.org/10.5014/ajot.56.6.609

BARDIN, L. Análise de conteúdo. Tradução de Luís Reto e Augusto Pinheiro. Lisboa: Ediçóes 70, 2009.

BRASIL. Ministério da Educação - MEC. Secretaria de Educação Especial - SEESP. Política Nacional de Educação
Especial na Perspectiva da Educação Inclusiva. Brasília: MECSEESP, 2007. Documento elaborado pelo Grupo de Trabalho nomeado pela Portaria Ministerial no 555, de 5 de junho de 2007, prorrogada pela Portaria no 948 , de 9 de outubro de 2007. Disponível em: <http://portal. mec.gov.br/seesp/arquivos/pdf/politica.pdf $>$. Acesso em: 31 out. 2010.

BRASIL. Ministério da Educação - MEC. Secretaria de Educação Especial - SEESP. Programa de Implantação de Salas de Recursos Multifuncionais. Brasília: MECSEESP, 2008. Disponível em: <http://portal.mec.gov.br/index. php?option=com_content $\&$ view $=$ article $\&$ id $=112 \& \mathrm{It}$ emid $=86>$. Acesso em: 20 nov. 2009.

CANADIAN ASSOCIATION OF OCCUPATIONAL THERAPISTS POSITION STATEMENT. Assistive Technology and Occupational Therapy. Canadian Journal of Occupational Therapy, v. 70, n. 2, p.113-8, abr. 2003. LAW, M. Avaliando papéis e competência. In: TROMBLY, C. A.; RADOMSKI, M. V. (Org.). Terapia Ocupacional para Disfunçōes Físicas. Tradução de Beatriz B. G. Schlecht, Maria Cristina Anauate, Maria Cecília F. Brandão, Maria Cecília E. Denes. São Paulo: Livraria Santos Editora Ltda, 2005. p. 31-46.

PELOSI, M. B. A Comunicação Alternativa e Ampliada nas escolas do Rio de Janeiro: formação de professores e caracterização dos alunos com necessidades educacionais especiais. 2000. 225 f. Dissertação (Mestrado em Educação)-Faculdade de Educação, Universidade do Estado do Rio de Janeiro, Rio de Janeiro, 2000.

PELOSI, M. B. Inclusão e Tecnologia Assistiva. 2008. 303 f. Tese (Doutorado em Educação)-Faculdade de Educaçáo, Universidade do Estado do Rio de Janeiro, Rio de Janeiro, 2008. v. 1 e 2.

\section{Contribuição dos Autores}

Miryam Pelosi: Concepção e redação do texto; Vera, Rodrigo, Lindinete e Lila: concepção do texto. Todos os autores aprovaram a versão final.

\section{Notas}

${ }^{1}$ Parte do projeto de pesquisa Formação de Professores das Salas de Recursos Multifuncionais para o Desenvolvimento da Comunicação Alternativa com os Alunos com Necessidades Educacionais Especiais, financiado pela Faperj por intermédio do Edital Melhoria das Escolas Públicas, 2009. O projeto foi submetido ao Comitê de Ética em Pesquisa em Seres Humanos do Hospital Universitário Clementino Fraga Filho - HUCFF/UFRJ, sendo registrado e aprovado sob número 075/10. Trabalho apresentado em formato de poster no XII Congresso Brasileiro de Terapia Ocupacional e IX Congresso Latino Americano de Terapia Ocupacional, em São Paulo, SP, Brasil, 2011.

${ }^{2}$ Um website é um conjunto de páginas na web, organizado com hipertextos acessíveis, geralmente pelo protocolo HTTP na internet. As páginas em um site sâo organizadas a partir de um URL básico, onde fica a página principal, e geralmente residem no mesmo diretório de um servidor. As páginas são organizadas dentro do site, em uma hierarquia observável no URL, embora os hiperlinks entre elas permitam que o usuário navegue de diferentes maneiras, a partir do seu próprio interesse. Pode ser chamado, também, de site, ou sítio eletrônico ou sítio, considerando o português de Portugal.

${ }^{3}$ O site BoardmakerShare está disponível em: http://www.boardmakershare.com/

${ }^{4} \mathrm{O}$ compartilhamento de atividades do site Imagina está disponível em: http://actividades.imagina.pt/

${ }^{5}$ O site está disponível no endereço: http://aex.intellitools.com 
${ }^{6}$ O compartilhamento de atividades está disponível em: http://www.sensorysoftware.com/onlinegrids.html

7 O Dropbox é de um disco virtual, com funçóes de armazenamento e compartilhamento de arquivos e pastas on-line. A troca de arquivos entre usuários é totalmente segura, pois a transferência de arquivos usa SSL (Secure Sockets Layers). Uma de suas vantagens, além de fácil utilização, é a simplicidade da sua interface. Uma página simples, mostrando suas pastas e as últimas atualizaçôes feitas por você ou por alguém que esteja compartilhando a informação.

${ }^{8}$ Portal de Tecnologia Assistiva do Curso de Terapia Ocupacional da UFRJ. Disponível em: www.portalassistiva.com.br

${ }^{9}$ O software PowerPoint compóe o conjunto de aplicativos do programa Microsoft Office, sendo mais comumente utilizado para a construçáo de apresentaçóes de ideias e projetos. Por sua facilidade de programação e sua disponibilidade na maior parte dos computadores dos professores, em casa e nas escolas, foi um recurso também utilizado na composição do material do curso de formação em CAA.

${ }^{10} \mathrm{BDR}$ é o formato dos arquivos produzidos a partir dos softwares Boardmaker e Speaking Dynamically Pro. Esses arquivos só podem ser abertos por pessoas que possuam os programas.

${ }^{11} \mathrm{PDF}$ é o formato de arquivo do software gratuito Adobe Reader e que pode ser aberto em todos os computadores que tenham esse programa instalado. Quando a atividade é salva nesse formato não permite a sua utilização de forma dinâmica no computador, mas o usuário pode imprimi-la e usá-la como recurso de comunicação ou atividade pedagógica em papel.

${ }^{12} \mathrm{~A}$ forma de acesso ao computador, fazendo uso de um acionador externo, pode ser feita por meio de um mouse adaptado. Esse mouse permite que um acionador que simula o clique do botáo direito ou esquerdo do mouse seja acoplado, permitindo que usuários com dificuldades motoras graves acessem programas com sistema de varredura e, assim, possam se comunicar com recursos de voz ou pela escrita. 